\title{
Sustainable Accomplishment of Solar E-waste Recycling -A Review
}

\author{
${ }^{1}$ Bhaskar GV, BNMIT, bhaskar18me007@bnmit.in ${ }^{2}$ Shashank R, BNMIT, shashank18me045@bnmit.in \\ ${ }^{3}$ Srinivasan H, BNMIT, srinivasan18me048@bnmit.in ${ }^{4}$ Santhosh M, BNMIT, santhosh18me044@bnmit.in \\ ${ }^{5}$ Champa PN, Assistant professor, Department of EEE, BNMIT, champapn@ bnmit.in
}

\begin{abstract}
The hierarchy of waste refers to the "3 Rs" i.e. Reduce, Reuse and Recycle, which implements the strategies of waste management according to their specifications in terms of waste minimisation. The power of solar was exposed to people when Jawaharlal Nehru National Solar Mission (JNNSM) was introduced in the country in the year 2010.From then on people started to install and set up the solar as they came to know that the end life of it is around to be 2035. But none of them thought about future, i.e. what would happen to the solar panels when they are not able to generate power. Now the main issue is how will India be able to discard nearly $90 \mathrm{GW}$ worth solar panel in the next 20 years? Where an average solar panel sized 250 watts, $90 \mathrm{GW}$ will amount to almost 7.7 million tonnes of E- waste at the end of a lifetime of a solar plant [1]. This paper mainly focuses on how these E-wastes produced can be reused and recycled.
\end{abstract}

Keywords: Photovoltaic (PV), Silicon, Reduce, Reuse, Recycling

\section{I-Introduction}

In the recent years, Photovoltaic (PV) has become the peak used renewable technology in the entire world. The solar panels are made of PV cells which converts sunlight to electricity. This photovoltaic energy can be used almost for small to large applications which requires electricity. The operation of these renewable systems does not produce any toxic-gas emissions, noise or greenhouse gases. They majorly contribute for the reduction of $\mathrm{CO}_{2}$. The PV energy can help meeting the demand for electricity growing worldwide, without experiencing the effect on environmental. The life span of the PV cells is made to last more than 25 years. This means that after 25 years of usage it still gives $75 \%$ efficiency. The commonly used PV cells is crystalline - silicon technology which holds accounting for 80$85 \%$ of technology share [2].

The biggest PV Installation is in Europe, which holds nearly $75 \%$ of the overall installed capacity in the world. Knowing about current quantity of accession of PV panels, the amount of waste is approximated to be around 9 million tonnes by 2050, so entire future depends on recycling of the PV panels [2]. Landfills are dangerous to undergo because these solar panels contain toxic material like lead as they can leach out when they breakdown, so it leads to a new environmental hazard. The department of renewable energy trusts that disposal of PV panels depends on the institutor.

\section{SOLAR CELLS: BENEFITS AND CHALLENGES}

- Environmental-friendly

- Abundant in nature

- Low operating costs

- Solar power requires high initial investment

- Storage of solar energy is expensive 
- Solar cells recycling process is pricey and might be toxic.

\section{Why Recycling of PV cells required?}

The growing photovoltaic technology is a new concern over End-of-life (EOL) solar panels is emerging. Nearly around $630 \mathrm{GW}$ of solar have been surpassed at the end of 2019. At 2020, nearly $110 \mathrm{GW}$ of new PV volume is expected, and in 2021 the installed volume could be $150 \mathrm{GW}$. It is anticipated to increase to $4500 \mathrm{GW}$ by 2050 , only if government bears renewables in their covid-19 economic recuperation plans [3].

The silicon-based solar panels recycling process begins with dismantling the original product by separating aluminium and the glass parts. Nearly $95 \%$ of the glass can be recovered, whereas the other metal parts are used for re-modelling cell frames. Solar cells are broken after a while due to various reasons and subsequently, several toxic materials such as $\mathrm{Cd}, \mathrm{Pb}$, and $\mathrm{Cr}$, are released into the environment causing saviour problems.

Main reason for failure are:

Considering Energy Strategy Reviews 27 (2020) 100431: Average solar panels lifetime is considered around 25 years; by 2050 the solar cell waste in entire world can be approximated to reach up to 75 billion $\mathrm{kg}$. Consider a thin-film PV cells, that contains significantly high toxic elements compared to traditional one (e.g., poly-crystalline and mono-crystalline). Telluride, gallium, selenium, arsenic, indium, and cadmium, for example, can have serious environmental consequences. Thin-film PV technology can be regarded the fastest growing market among renewable systems, both in terms of performance and potential, with growth from $40 \mathrm{GW}$ in 2013 to $500 \mathrm{GW}$ in 2020 . As a result, we cannot refuse technology, but we must take care of the materials utilized and reflect in a systematic way on the recycling process in order to avoid future environmental conflicts. In fact, only around $10 \%$ of PV modules in the world are recycled due to a shortage of recycling sectors (Refer Figure 1).

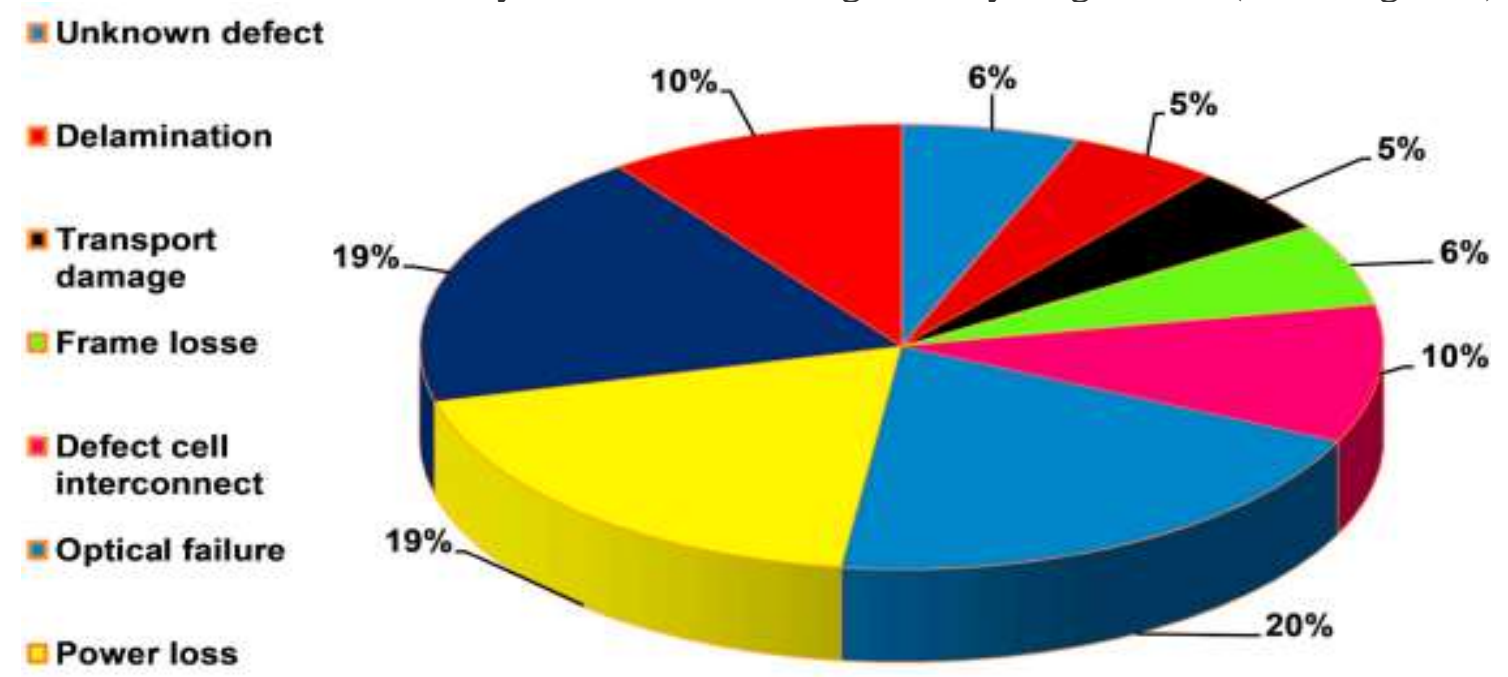

w Junction box and cables

= Glass breakage

Figure 1: Percentage analysis of Recycling PV module 


\section{Recycling Processes:}

To reuse silicon from PV modules generalised sequences should be followed as shown in figure 2, which have been revealed on pre-industrial pilot plan

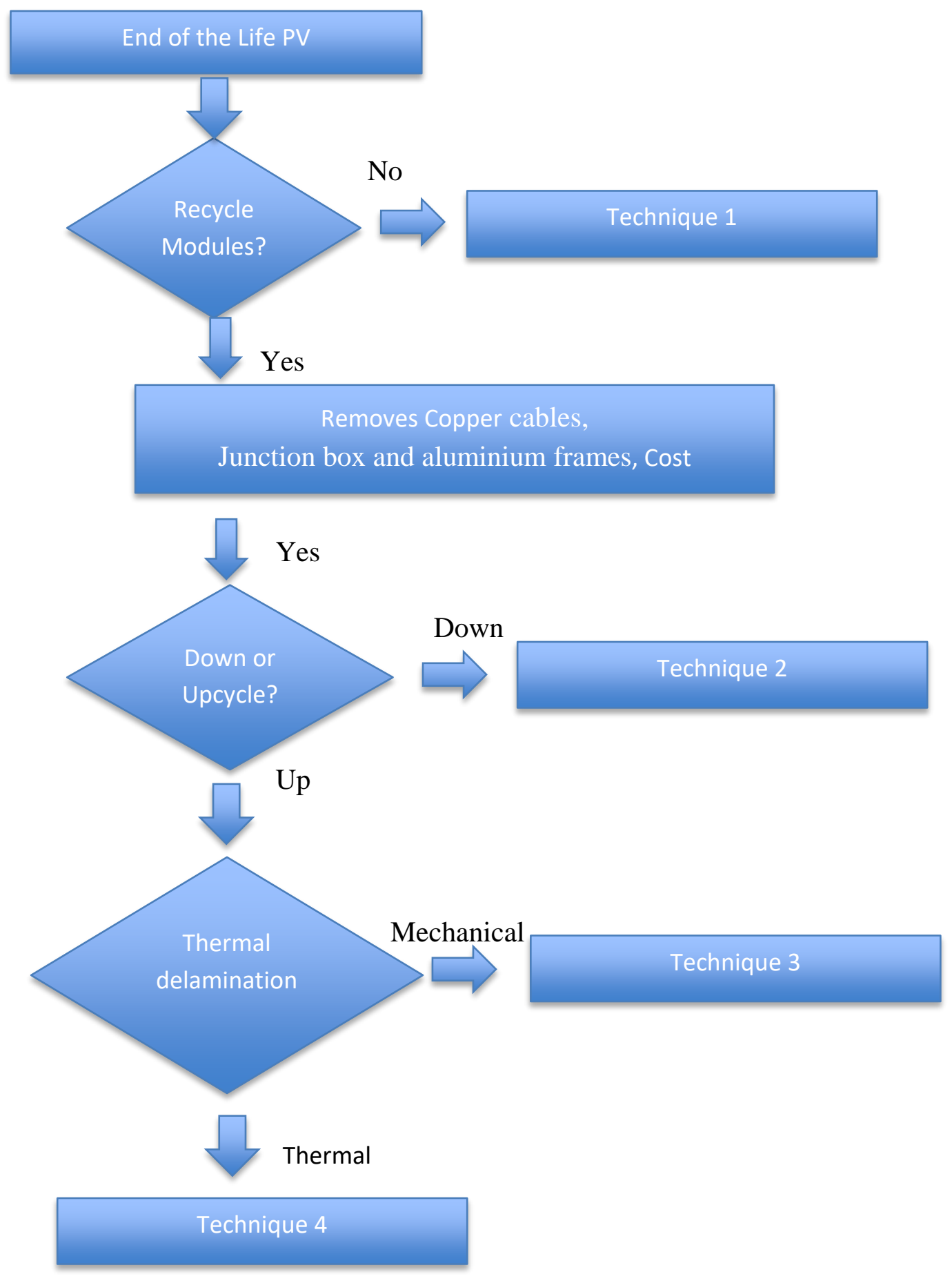

Figure 2: PV modules generalised sequences 
At first copper cables, aluminium frames and junction box are removed.

Next, glass is split and recycled by mechanical cutting or shredding. Successively, in down cycling approach disposes the remainder components into landfill, whereas the up-cycling approach further uses pyro-metallurgical/hydro-metallurgical method to recycle and reuse pure silicon and some metal components. Currently, thermal delamination is used to obtain highly pure Silicon wafers and unbroken solar cells [4].

The four basic recycling methods/techniques in our analysis as shown in the figure 3:

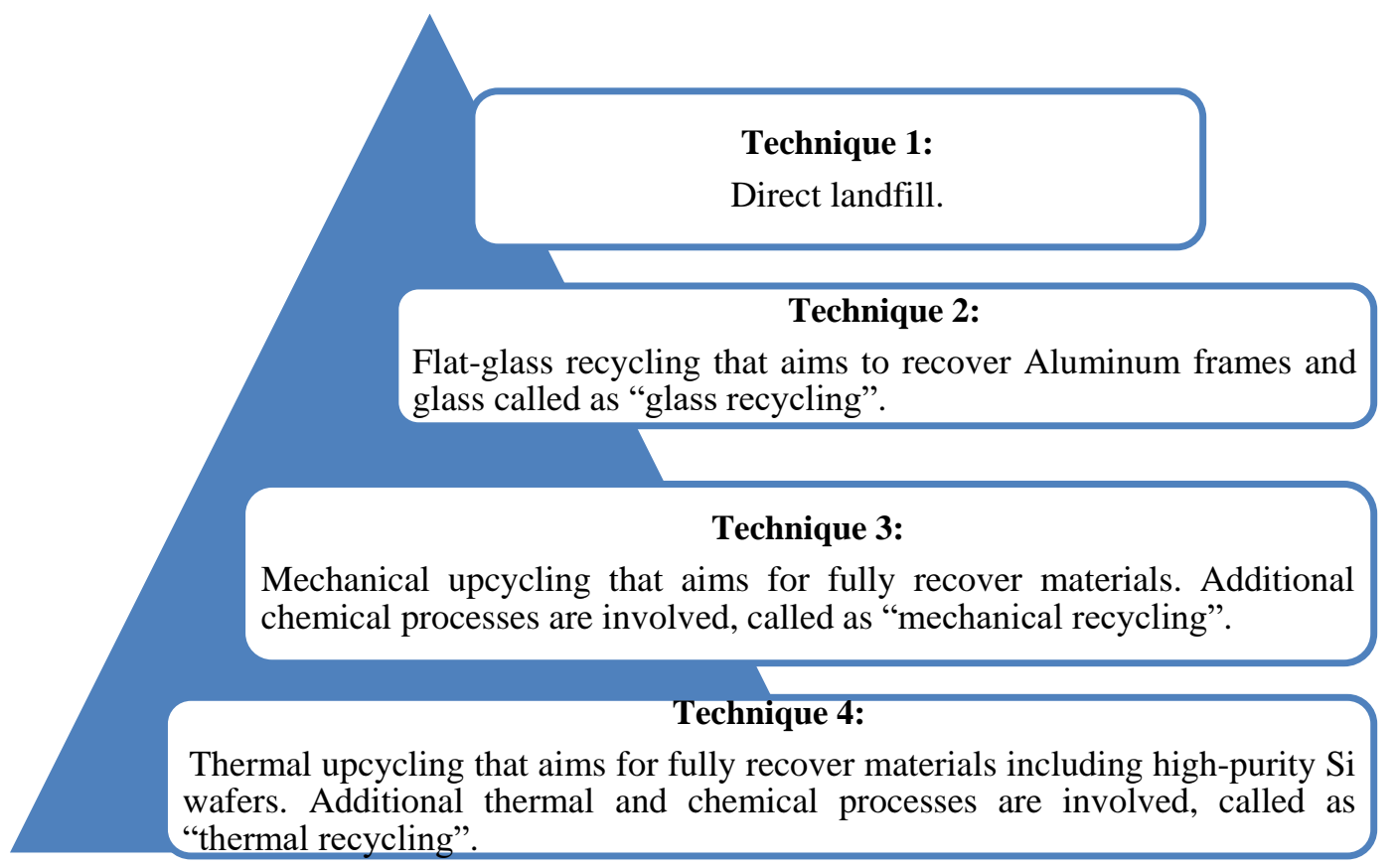

Figure 3: Basic recycling methods/techniques used for analysis

Basically there are different types of recycling process. In order to have high potential environmental impacts and to get maximum efficiency from the recycled products in this paper we have focused on two different methods that follow the generalised sequences to recycle silicon from modules, as shown in flowchart.

1. Overall input and output of recycling process

2. Solar cell recycling feasibility technique

\section{Overall input and output of recycling process}

The present study involves the treatment of fluorine back-sheet PV waste for $1000 \mathrm{~kg}$ of PV panels as input of recycling process that corresponds to the flowchart described in Figure 3.

Transportation of PV waste is the first step in this process:

Initially, wastes are taken into plant where unloading is done, using forklift it is transferred into conveyor belt for dismantling process. Here edges of aluminium frames are separated. Afterword, PV waste are transferred into next process where the cables are detach using mechanical arm. As a result, 
cables and aluminium frames are separated from photovoltaic cells, polymers, glass. The aluminium frames are collected, while the cables are transported to a different facility for further processing. The detachable plastics from the cables are disposed of in an energy-recovery incineration chamber. The glass layers are separated from the remaining layers of cells and polymers in the glass separation process, which is known as PV sandwich [2-5]. PV glass and PV sandwich are the end products of this procedure. The glass fragments are sent to the glass refinement process. The glass is divided into different diameters in this procedure. Only about $2 \%$ of the total mass is discarded. A cutting procedure reduces the size of the PV sandwich layer. Later, an incinerator plant was used to treat the waste. The output of incineration is composed by the residual bottom ash ( $40 \%$ of the input). The ashes which are produced are sent to landfill that are hazardous waste. The energy produced during incineration which is recovered in the form of heat and electricity. The bottom ash is further treated in recycling plant and this ash is sieved to collect the residues aluminium connector, then it is transferred to acid leaching process.

The goal of this method is to separate silicon from other metals in the ash. The ash containing metals is mixed with water and a nitric acid (HNO3) solution during the leaching process, which dissolves the metals and leaves silicon metal in leftovers. The dissolved combination of metallic oxides and silicon metal residues is passed through a vacuum filtration process. Electrolysis treatment is done for the remaining silicon metal and the other dissolved metals in acid solution. Silver and copper are recovered with the efficiency of 95\%. The acid solution remaining in electrolysis is successively neutralized by addition of calcium hydroxide [2]. The final product of the neutralisation process is subsequently filtered by a filter press, which can separate a liquid waste from sludge containing unrecovered metals and some residual water. Finally, these materials are transferred to various landfills for final disposal. The overall input and output of recycling process in different sectors are explained in Figure 4.

\section{Advantages}

- The glass pieces are separated in different sizes of diameters varying from (1 - 2.5) $\mathrm{mm}$, and $(2.5-5) \mathrm{mm}$ by sieving in glass refinement process.

- The output of incineration is composed by the left over ash at the bottom about $40 \%$ of the input.

- During the electrolysis process copper and silver are recovered, both with an $95 \%$ of efficiency.

- Recovering the silicon metal and recirculate a part of the acid solution about $80 \%$ in vacuum filtration process.

- At metallurgical grade about $95 \%$ of silicon is recovered in acid leaching process

\section{Disadvantages}

- The efficiency of aluminium separation is approximately around $50 \%$.

- The gases released during incineration process are harmful and leads to global warming. 


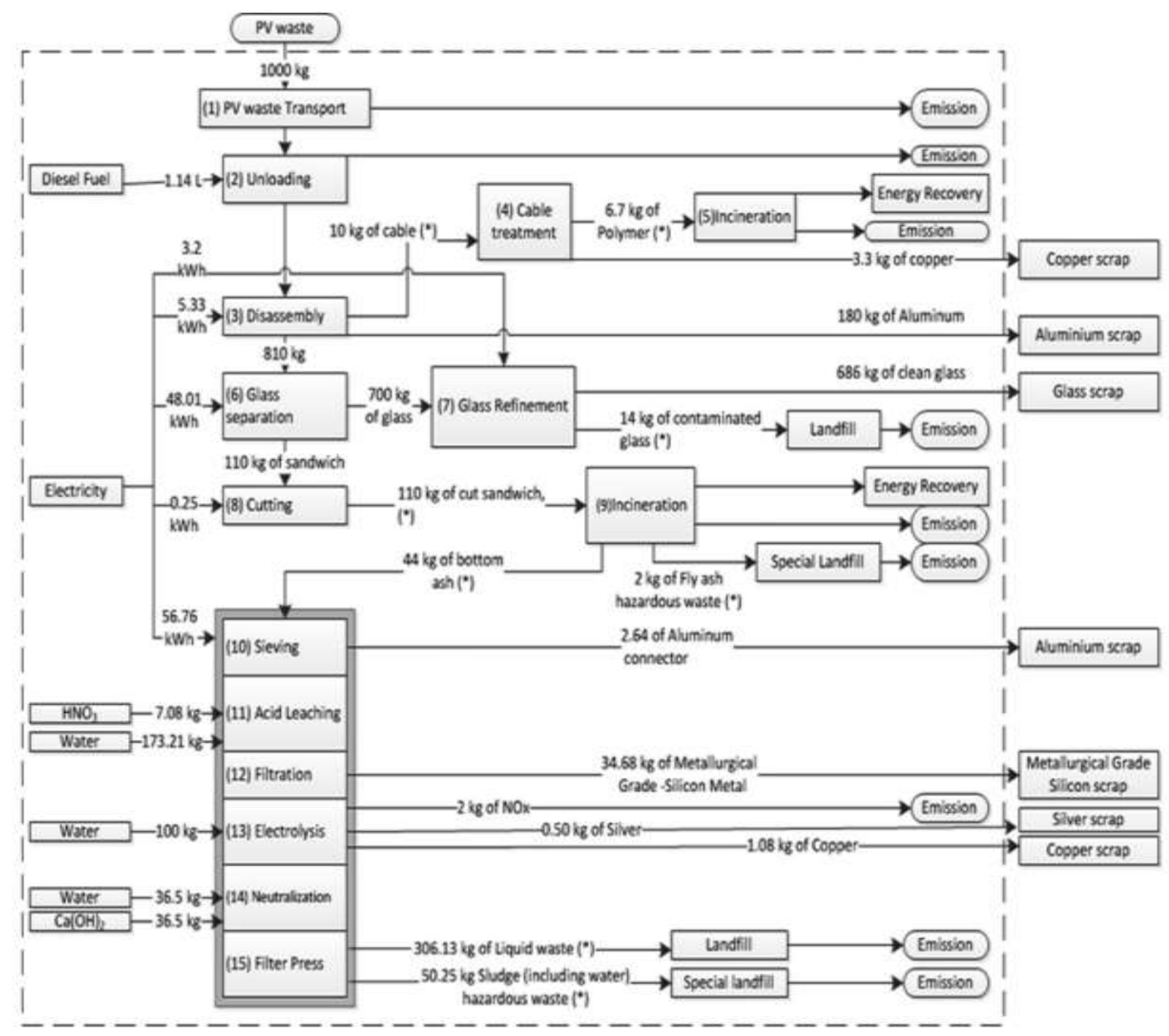

Figure 4: Overall input and output of recycling process

\section{Solar cell recycling feasibility technique}

Primarily, the amount of scrap generated by a typical manufacturing of PV-module Facilitate, a steady -state level of production achieved within six months. For example, approximately 2000 ton of solar panels were produced annually where $10 \mathrm{MW}$ of electricity is generated. About $0.1 \%$ of semiconductor material is used others are mainly glass. We should distinguish between the future needs and near term of PV recycling process, and its capabilities. Centralized approaches is to be needed whereas large-scale would be the more economical in future. Centralized and Decentralized strategies are discussed below:

\section{Centralized strategies}

Large smelters like computer monitors, recycle circuit boards, telecommunication equipment and consumer electronics are recover metals. In today scenario only small amount of scrap is recycled by PV manufacturers. The PV modules of low concentrated metals and generated scrap doesn't have any recycling value significantly but the contented glass of their metals to smelter operators has a certain value for fluxing operation silica is purchased. Therefore, to reduce the treatment costs, which is presently around Rs. 13,040 - Rs. 14,900 per ton [6]? 
In copper smelters selenium, tellurium, cadmium and contact metals (Eg: Ni) can be treated. Where a liquid metal bath reactor convertors and anode furnaces is processed by shredding. In fluxing operation of the smelters the shredded glass content is used, the plastic decomposes and ethylene vinyl operates at very high temperature of the smelter into monomeric vapours and carbon dioxide. The copper refinery is processed by anodes where selenium and metallurgical grade of tellurium is electrolytically recovered. In molten copper cadmium does not dissolve but waste streams of the copper smelter remain same, cadmium of a zinc smelter can be recovered, but the tellurium and other metals of CDTE scrap cannot be accepted so the process is sensitive.

The recycled CIS solar panels cost is projected approximately Rs 8.20 per w. Metals like lead and cadmium in solar panel and their concentrated is minuscule (extremely small, tiny) it causes a classification of hazardous waste from these it senses to glass has been separate from these metals (which is the bulk of a solar panel) it can be alone economically.

\section{De-centralized strategies}

During this process hazardous metals are separated from the solar panel in order to accomplish a hazardous waste reduction. Basically in this process, from glass metals can be stripped by either physical or chemical methods physical method includes pyrolysis, hammer mill and sand blasting whereas chemical method includes appropriate solvents like acid and oxidizers, to recover the metals it is the most effective way. The metal which can be treated the liquid either of the following ways:

i. By conventional method of metals precipitating as hydracids, by accumulating as sludge and disposing at a waste site.

ii. By concentrating metals in solution and recycling the solution within plant by ion exchange or reverse osmosis and dialysis.

iii. The metals are directly recovered by electrochemical methods.

Hydroxide precipitation is simple to operate and common method as it is relatively. There are some advantage of sulphide precipitation but oxidation - reduction potential (ORP) and $\mathrm{pH}$ must be minimize carefully controlled the risk of producing hydrogen sulphide gas in toxic levels. Using sulphide precipitation and hydroxide, is an option in two sequential steps, particularly where chelates or complexes are present. Using calcium carbonate or sodium, will be helpful, for soluble lead reduction

The precipitation of phosphate is also an option this is not a common process. This article reviews technical applicability and recent development of various treatments for heavy metals removable from industrial wastes. For innovative physio-chemical removal process a particular focus is given such as: membrane filtration, photo-catalysis and electro-dialysis. The main conditions such as treatment performance and $\mathrm{pH}$ are present.

Electrochemical methods recover highly and remove metals based on principle the precipitated on metals at elementary form of solid when the electricity on the electrode is applied. These are their functions of reductions are of three types. Electro flotation (EF), electrode position and electrocoagulation (EC). The use of electrodes of EC involves then metals wire react with the coagulating ions and these coagulates separated later by centrifugation. Owing to three ways, the most commonly used method is hydroxide precipitation, because most metals can be precipitate at alkaline $\mathrm{PH}$, but during the solution 
concentrated techniques, the most effective one is ion exchange, but is more expensive compared to precipitation [6].

A process was introduced by solar cells including recycling of CdTe modules, which starts with separation of a module and recovers of lead wires, then the modules are crushed and the parts of it are separated. The metals are stripped off from the crushed glass by chemical dissolution or precipitation and at the end glass and EVA are recovered completely, then the remaining metals like $\mathrm{Cd}, \mathrm{Te}, \mathrm{Su}, \mathrm{Al}$, and $\mathrm{Cu}$ are sent to INMETCO where $\mathrm{Cd}$ is recovered and used as feed stock for batteries as shown in the figure 4.

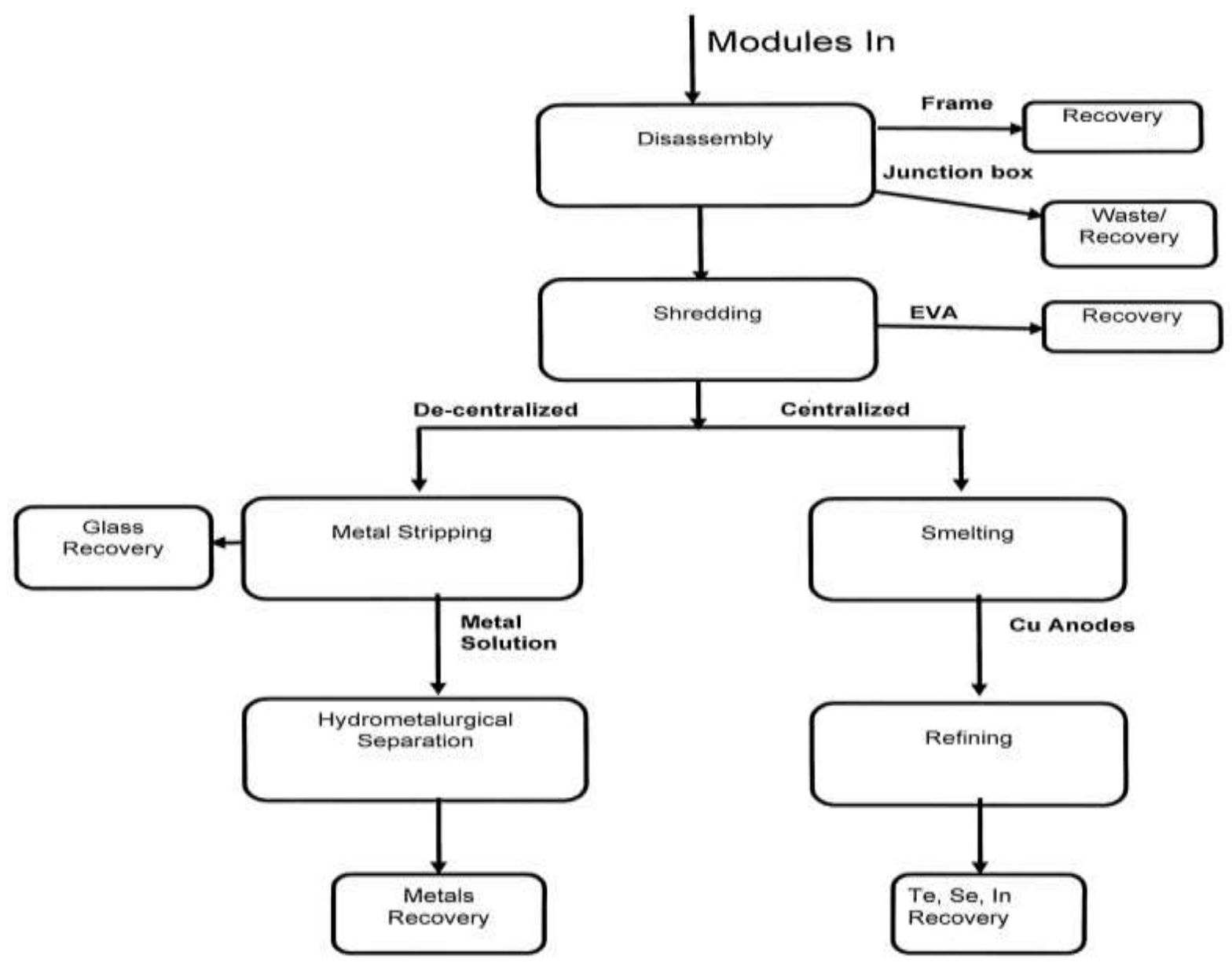

Figure 4: PV module and scrap recycling options

\section{Advantages}

- Recover of high purity materials.

- Full removal of EVA.

- Low energy requirements.

- Easy access to the EVA.

- Easy removal of glass.

- Cost effective.

- Inexhaustible, abundant supply 


\section{Disadvantages}

- Harmful emissions

- Cell defects and degrades due to very high temperature.

- Full EVA removal is required for other separation process.

\section{Results:}

The expansion of possible PV recycling processes for PV modules, including silicon-based and thin-film technologies, was examined in this paper. The recycling of silicon modules has been proposed, and while it is more expensive than dumping them in a landfill, it can ensure the supply chain's long-term sustainability by increasing the energy recovery rate and implant materials, while reducing the emissions of $\mathrm{CO} 2$ for all PV panels. The inefficiency of current approaches does not imply that solar PV module recycling should be abandoned. PV waste management has the potential to create a new path for industry development and provides job opportunities for both private and public sector players.

It is widely acknowledged that the recycling of End of Life solar modules has a positive impact on the environment. Solar modules can be recycled to remove and keep potentially dangerous chemicals like selenium, cadmium, and lead. It can also collect and make available rare materials such as indium, silver, and tellurium for future use. In order to achieve the best possible results at the lowest possible cost, the future recycling process must keep up with ongoing restyling in solar cell and module technology.

If we compare the economy of telecommunications and recycling electronics, where the benefits are generated through the retrieval of valuable metal and its parts, unlikely for PV modules to have abundant amounts of these components to pay for the costs of steps to processes that as to be recycled. It is necessary that specific measures and policies for recycling and PV waste management of modules should be considered before the quantity of E-waste are removed from existing modules becomes startling, as prediction of the year 2035[7].

\section{Conclusion:}

By comparing all the processes, the process 1 is the most efficient and feasible one because during the electrolysis process the main parts like silver and copper are recovered at a good rate and at high efficiency of $95 \%$ and even during the filtration process the silicon metal is recovered at an efficient rate. In this process the waste cables and the plastic parts are sent to the landfill, and the energy produced during this incineration are used as source for electricity. 
Therefore, recycling process for solar E-wastes are explored not only in laboratories and prototype models, but many are also available in markets/Industries (commercially). It is also evident that with majority of challenges such as recovering more materials, economic feasibility etc., still continue to exist in process efficiency, convolution energy requirements and use of non-environmentally favourable materials for the care of some elements.

\section{References:}

[1] What about recycling for solar PV?

https://www.downtoearth.org.in/news/energy/what-about-recycling-for-solar-pv--54797

[2] Cynthia E.L. Latunussa a , Fulvio Ardente a,n, Gian Andrea Benign a,b Lucia Mancini a Solar Energy Materials \& Solar Cells www.elsevier.com/locate/solmat.

[3] Authored by Attila Tamas Veko, Recycling: Solar panel after death https://www.greenmatch.co.uk/blog/2017/10/the-opportunities-of-solar-panel-recycling. [4] A Techno-economic review of silicon photovoltaic module recycling Rong Deng* , Nathan L. Chang, Zi Ouyang, Chee Mun Chong School of Photovoltaic and Renewable Energy Engineering, University of New South Wales, Sydney, NSW 2052, Australia.

https://www.solarfeeds.com/mag/recycling-problems-with-photovoltaic-technologies/ [5] A Review of Recycling Processes for Photovoltaic http://dx.doi.org/10.5772/intechopen . [6] End-of-life management and recycling of PV modules: Vasilis M. Fthenakis.

[7] A Review of recycling processes for photovoltaic Modules Marina Monteiro Lunardi, Juan Pablo Alvarez-Gaitan, José I. Bilbao and Richard Corkish, Submitted: November 9th 2017Reviewed: January 25th 2018Published: February 15th 2018 DOI: 10.5772/intechopen.74390. 